\title{
Reduction of matrix metalloproteinase-9 expression by culture filtrate of Paecilomyces farinosus $\mathrm{J3}$
}

\author{
HYUN-JIN LEE ${ }^{1 *}$, CHUL-HONG PARK ${ }^{1 *}$, HYUNG-U SON ${ }^{1}$, JIN-CHUL HEO ${ }^{2}$, SUNG-HEE NAM ${ }^{5 *}$, \\ KWANG-GIL LEE ${ }^{5}$, JOO-HONG YEO ${ }^{5}$, CHEOL-SIK YOON ${ }^{6}$, JONG-MYEUNG KIM ${ }^{3}$, \\ YONG-KYU SHIN ${ }^{3}$, SI-OH KIM ${ }^{4}$ and SANG-HAN LEE ${ }^{1,2}$ \\ ${ }^{1}$ Department of Food Science and Biotechnology; ${ }^{2}$ Food and Bio-Industry Research Institute, Kyungpook National University; \\ ${ }^{3}$ Bion Co., Ltd., Daegu 702-701; ${ }^{4}$ Department of Anesthesiology, Kyungpook National University School of Medicine, \\ Daegu 700-412; ${ }^{5}$ Department of Agricutural Biology, National Advanced Institute of Science and Technology, \\ RDA, Suwon 441-707; ${ }^{6}$ Mycoplus Co., Ltd., Uiwang 437-820, Republic of Korea
}

Received November 16, 2010; Accepted January 17, 2011

DOI: 10.3892/etm.2011.214

\begin{abstract}
The aim of the present study was to investigate the anti-tumor effects of a culture filtrate of Paecilomyces farinosus J3. Various anti-tumor assays using B16 melanoma cells were carried out. Paecilomyces farinosus $\mathrm{J} 3$ significantly decreased the wound healing capability, invasiveness and angiogenic activity, which was confirmed by wound healing, human umbilical vein endothelial cell and invasion assays. Paecilomyces farinosus $\mathrm{J} 3$ strongly inhibited cell migration, tube formation and the angiogenic process in a concentrationdependent manner. Zymographic analysis also indicated a reduced expression of matrix metalloproteinase-9 (MMP-9), a 92-kDa gelatinase. Taken together, the results indicate that the anti-tumor activities of Paecilomyces farinosus $\mathrm{J} 3$ originate from the reduction of MMP-9 expression in B16F10 cells.
\end{abstract}

\section{Introduction}

Cancer is a progressive disease that affects many types of tissues, as well as organs, in the human body (1). Cancer progression and metastasis is a complicated process. Cells move through the blood and invade neighboring tissue by degrading the extracellular matrix (ECM) (2). In these multiprocesses, angiogenesis plays a pivotal role in the formation of new blood vessels in the newly colonized areas, and thus in the formation of additional metastatic lesions $(3,4)$. The ECM includes a wide variety of proteins, which can be degraded by

Correspondence to: Professor Sang-Han Lee, Department of Food Science and Biotechnology, Kyungpook National University, Daegu 702-701, Republic of Korea

E-mail: sang@knu.ac.kr

*Contributed equally

Key words: Paecilomyces farinosus J3, culture filtrate, anti-tumor activity, wound healing, invasion, matrix metalloproteinase-9 many matrix metalloproteinases (MMPs). MMPs are a family of highly conserved zinc-dependent peptidases capable of degrading the ECM (3).

Anti-tumor agents have been shown to inhibit MMP-9 activity in the ECM via the binding of the NF- $\kappa \mathrm{B}$ transcription factor with the MMP-9 promoter (5). This suggests that anti-tumor agents play a role in anti-invasion and/or anti-angiogenesis, as well as in caspase-3 inhibition (6). Cell motility, and in particular cell migration, affect tumor progression and metastasis (7). The signaling pathways responsible for regulating cell motility involve various nuclear transcription factors, as well as morphological changes in the cytoskeleton that modify interactions among membrane- and ECM-bound proteins (e.g., cdc, Rho and Rac family proteins), which mediate cellular and membrane morphology by controlling the polymerization-depolymerization process of the actin cytoskeleton (8).

Cordyceps and Paecilomyces sp. are popular entomopathogenic fungi, which have been broadly called DongChungHaCho (winter worm summer grass) in Korea (8-11). Paecilomyces $s p$. has been investigated for industrial purposes in order to be cultivated on a large scale. However, the precise biological mechanisms of functionality and bioavailability require investigation.

In this study, we show that Paecilomyces farinosus J3, which was collected and isolated from Mansusan, Korea, decreases cell migration, invasion and tube formation, suggesting that this activity may have originated from the pathway of MMP-9 inhibition. Our findings, in combination with previous studies, strongly suggest that Paecilomyces farinosus J3 should be considered a good candidate for development into an antitumor therapeutic agent, as well as in anti-tumor preventive medicine, provided that MMP-9 is the major molecular target molecule for angiogenesis and tumor progression.

\section{Materials and methods}

Culture and separation of Paecilomyces sp. The strain Paecilomyces farinosus J3 was collected from Mansusan 


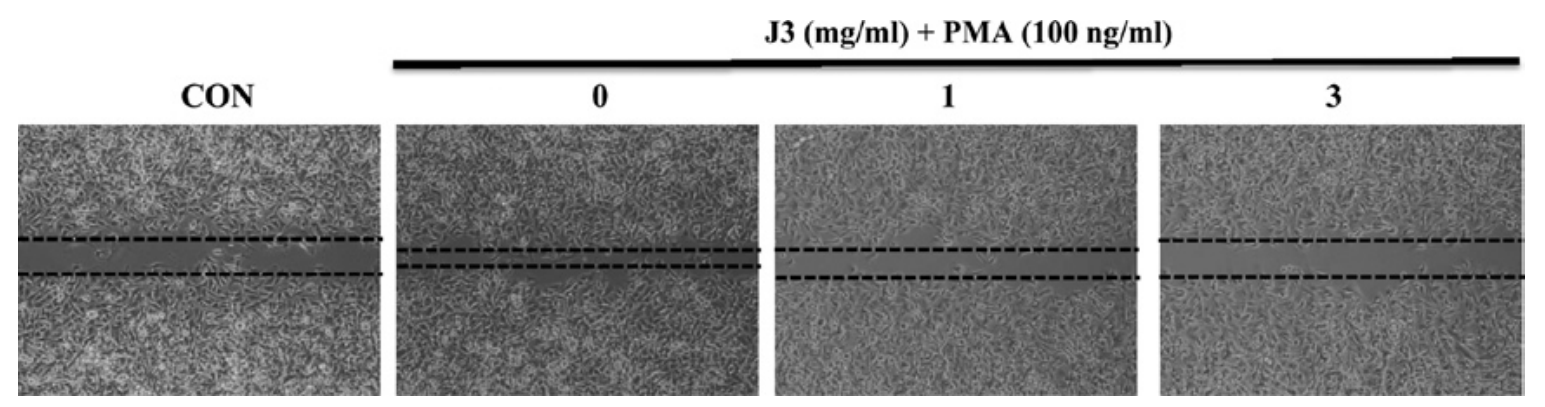

Figure 1. Paecilomyces farinosus $\mathrm{J} 3$ inhibits cell migration in vitro. (A) Confluent monolayers of B16 cells were pre-treated with or without the Paecilomyces farinosus $\mathrm{J} 3$ culture filtrate. The monolayers were then wounded and stimulated with $100 \mathrm{ng}$ PMA or left untreated (controls). The plates were photographed at 0 or $24 \mathrm{~h}$ post-wounding. Bar, $200 \mu \mathrm{m}$. (B) Quantification of the wound healing. Cell migration was quantified by counting the wound width $24 \mathrm{~h}$ after the plates were treated with or without PMA. Values are the means \pm SD from five cultures each in duplicate experiments. CON, control. *Significant difference from the control, $\mathrm{P}<0.05$. ${ }^{* *}$ Significant difference from PMA treatment alone, $\mathrm{P}<0.05$.

and deposited in the Collection Center of the Department of Agricultural Biology, National Advanced Institute of Science and Technology, RDA, Suwon, Korea. The strain was cultured and re-isolated in PDA medium ( $24 \mathrm{~g}$ potato dextrose, $15 \mathrm{~g}$ agar and 11 distilled water) at $25^{\circ} \mathrm{C}$ for 2 weeks. After sufficient maturation of the mycelial growth, the culture supernatants were centrifuged and divided into mycelial extract and culture filtrate. The culture filtrate was then freeze-dried under a vacuum evaporator. The freeze-dried powder of culture filtrate was dissolved in distilled water prior to use (12).

Cell culture. The mouse melanoma cell line B16F10 (B16; Catalog \#CRL-6323) and human umbilical vein endothelial cells (HUVECs) were purchased from the American Type Culture Collection (ATCC; Manassas, VA, USA). The B16F10 cells were cultured in RPMI-1640 medium supplemented with $10 \%$ FBS, while the HUVECs were cultured in EGM-2 medium (BD Biosciences, Lake Placid, NJ, USA). The B16F10 cells were maintained in RPMI-1640 medium and subcultured by trypsinization at 3- to 4-day intervals. The HUVECs were subcultured every 3-4 days and were used for experiments at passages 3-10 (13).

Wound healing assay. The strips of sterilized thin film tape $(2 \mathrm{~mm} \times 2 \mathrm{~cm} ; 3 \mathrm{M}$, Seoul, Korea) were attached to the bottom of each well of 6-well plates (Greiner, Frickenhausen, Germany), and the B16 cells were split into plates at a concentration of $1 \times 10^{7}$ cells/well, and allowed to grow for $6 \mathrm{~h}$ at $37^{\circ} \mathrm{C}$ in a $5 \% \mathrm{CO}_{2}$ atmosphere. The tape strips were then detached, creating linear wounds. The plates were photographed and incubated as described above with medium containing various concentrations of $\mathrm{J} 3(0-100 \mathrm{mg} / \mathrm{ml})$. The plates were photographed at $24 \mathrm{~h}$ and the precise wound width was calculated by use of a microruler (http://www.eeob.iastate.edu/ faculty/DrewsC/htdocs/microruler-links.htm) as described previously (14).

Invasion assay. Transwell plates (pore size $8 \mu \mathrm{m}$; Costar, NY, USA) were loaded with $100 \mu$ l Matrigel (BD Biosciences), allowed to solidify at $37^{\circ} \mathrm{C}$ for $2 \mathrm{~h}$ and then coated with $10 \mu \mathrm{l}$ of fibronectin $(200 \mu \mathrm{g} / \mathrm{ml})$. The plates were loaded with B16 cells suspended in $10 \%$ FBS $\left(1 \times 10^{5}\right.$ cells/well $)$, the samples were exposed to $\mathrm{J} 3(0-100 \mathrm{mg} / \mathrm{ml})$ and the plates were incu- bated at $37^{\circ} \mathrm{C}$ in $5 \% \mathrm{CO}_{2}$ for $24 \mathrm{~h}$. The migrated cells were fixed with methanol, stained with hematoxylin and counted under a microscope (15).

Tube formation assay. HUVECs ( $2 \times 10^{4}$ cells/well) were added to the Matrigel-coated 24-well plates in $0.5 \mathrm{ml}$ of EGM-2 medium with various concentrations of $\mathrm{J} 3(0-100 \mathrm{mg} / \mathrm{ml})$ and incubated for $24 \mathrm{~h}$. The cells were then visualized under a microscope and tube formation was scored by counting the number of tubes formed $(14,15)$.

Gelatin zymography. Gelatin zymography was performed as described previously (16). Proteins with gelatinolytic activity were identified by electrophoresis in the presence of SDS on $8 \%$ polyacrylamide gels containing $0.1 \%(\mathrm{w} / \mathrm{v})$ gelatin. In brief, cell culture medium was obtained from cultured B16F10 cells in DMEM and PMA (100 ng), with or without different concentrations of $\mathrm{J} 3$ for $24 \mathrm{~h}$ in 6 -well culture dishes. The cultured medium was mixed with an SDS-PAGE sample buffer in the absence of $\beta$-mercaptoethanol and DTT. Five microliters of sample were loaded onto a gel and electrophoresed. After electrophoresis, the gel was renatured twice for $30 \mathrm{~min}$ at room temperature in $2.5 \%$ (v/v) Triton X-100, and subsequently transferred onto a zymogram-developing buffer containing $50 \mathrm{mM}$ Tris- $\mathrm{HCl}, 5 \mathrm{mM} \mathrm{CaCl}_{2}, 0.2 \mathrm{M} \mathrm{NaCl}$ and $0.02 \%$ Brij 35 at $37^{\circ} \mathrm{C}$ overnight. After staining with Coomassie Blue R-250 (0.25\%) for $30 \mathrm{~min}$, the gel was then distained in a distaining solution [methanol:acetic acid:water (50:10:40)]. A clear band was detected and quantified using the BioRad GelDoc system.

Statistical analysis. Data are expressed as the means \pm standard deviation (SD). Statistical significance was determined by the Student-Newman-Keuls method for independent means, using the Sigma Plot program (17). The critical level of significance was set at $\mathrm{P}<0.05$.

\section{Results}

In a previous study, we developed various cultivation methods and cultivated various insect pathogenic fungi, including Paecilomyces sp. (DongChungHaCho in Korean). The morphology of the selected strain has a classical feature of mycelial growth that is common in entomopathogenic fungi 
A

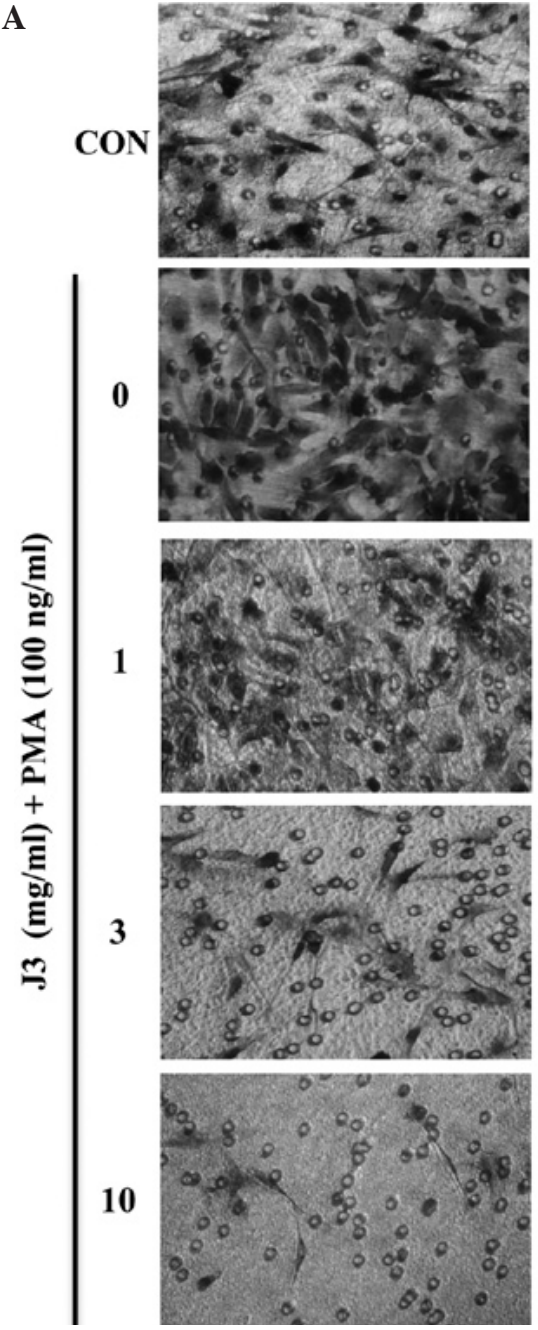

B

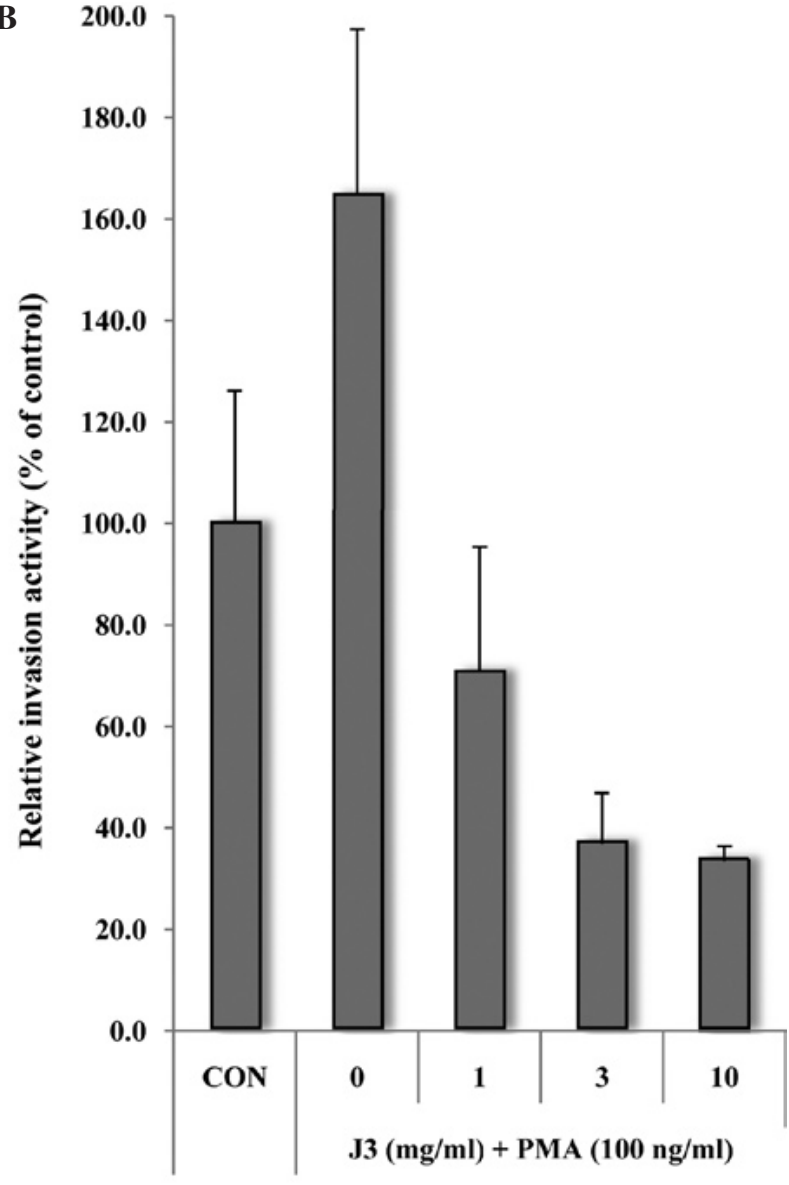

Figure 2. Paecilomyces farinosus $\mathrm{J} 3$ inhibits cell invasion in vitro. Cell invasion was assayed in a Matrigel-coated Transwell chamber. (A) Invasion was compared among B16 cells exposed to no treatment (control; a), $100 \mu \mathrm{g} / \mathrm{ml}$ of Paecilomyces farinosus J3 (b), $75 \mathrm{nM}$ PMA (c) and both Paecilomyces farinosus J3 and PMA (d). Representative fields of migrated cells were photographed. Bar, $200 \mu \mathrm{m}$. (B) Quantification of the invasion activity. Cell migration was quantified $24 \mathrm{~h}$ after the cells were exposed to no treatment (control; CON), Paecilomyces farinosus J3, PMA, or both Paecilomyces farinosus J3 and PMA Migrated cells were counted from five randomly selected microscopic fields and the results are given as the average per field \pm SD of three independent experiments. "Significant difference from the control, $\mathrm{P}<0.05$. ${ }^{* *}$ Significant difference from PMA treatment alone, $\mathrm{P}<0.05$.

(data not shown). In this study, we optimized the maintenance and culture medium of Paecilomyces farinosus $\mathbf{J} 3$ (data not shown), and investigated the biological activities of the culture filtrate of that strain. Few strains have been studied for their anti-tumor activities and their efficacy as culture filtrates.

We first examined the tumor cell motility of J3-treated B 16 cells. We used a wound healing assay to assess the in vitro effect of $\mathbf{J} 3$ on tumor cell migration, which is an important phenomenon of cancer cell motility, particularly in relation to metastatic cancer. The wound healing assay showed that the monolayers treated with $10 \mathrm{mg} / \mathrm{ml}$ of $\mathrm{J} 3$ displayed a clear wound width, while the untreated control monolayers exhibited complete wound healing within $24 \mathrm{~h}$, indicating that at J3 partially inhibits cell migration in vitro in a dose-dependent manner (data not shown). Notably, the PMA-treated monolayers also showed a cell growth inhibitory pattern (Fig. 1, 2nd to 4th lower images) as did the control, suggesting that J3 inhibited cell migration activity with or without a cell proliferation inducer. Similarly, the invasion assay revealed that $\mathrm{J} 3$ treatment $(10 \mathrm{mg} / \mathrm{ml})$ inhibited invasive activity by $>40 \%$ vs. the control group (Fig. 2A). These results indicate that J3 dose-dependently alleviates wound healing and inhibits invasion in vitro in a concentration-dependent manner (Fig. 2B).

We then investigated the effect of $\mathrm{J} 3$ on angiogenesis, which is a key feature of metastasis. HUVECs were treated with or without various concentrations of $\mathrm{J} 3$, and tube formation was measured in terms of tube size and number. The data demonstrated that J3 inhibits HUVEC tube formation in vitro in a dose-dependent manner (Fig. 3; 0.1-3 mg/ml). Notably, the cell tubular numbers were dramatically decreased by various doses of J3 (Fig. 3B, compare columns 2 and 5). Collectively, these findings indicate that $\mathrm{J} 3$ inhibits cell migration, cell invasiveness and tube formation in vitro, suggesting that this extract can function as an anti-tumor component in vitro by decreasing metastatic and/or angiogenic potential.

Zymographic analysis revealed that the treatment of cells with $0.1-10 \mathrm{mg} / \mathrm{ml}$ of J3 inhibited gelatinase (MMP-9; $92 \mathrm{kDa}$ ) by $\sim 45 \%$ (Fig. 4A), suggesting that J3 has a strong potential to hamper the secretion of the active form of MMP-9 rather than the activity level per se. The relative MMP-9 activity reached 
A

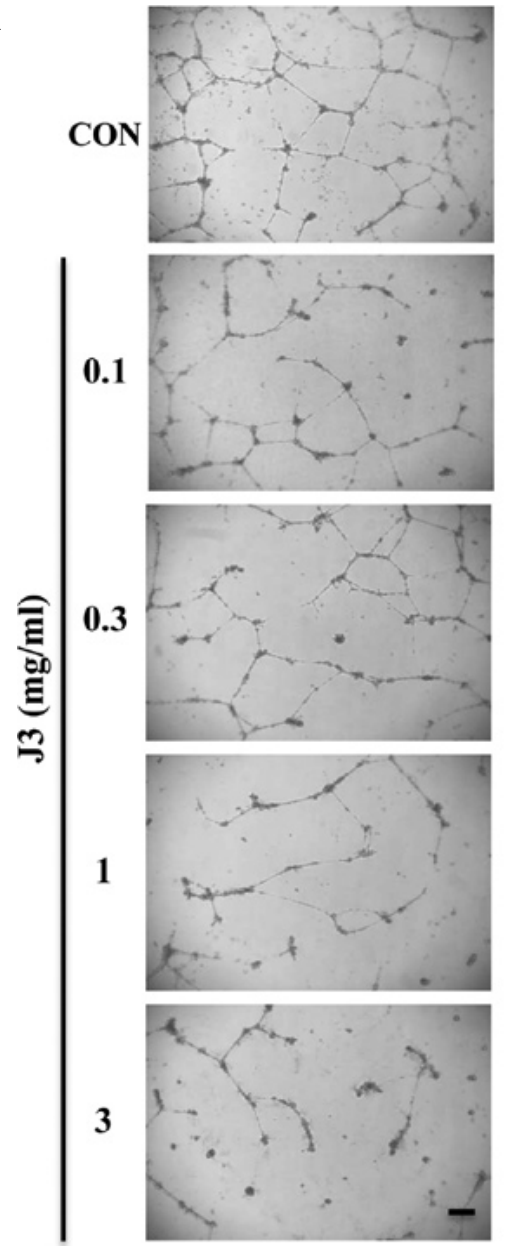

B



Figure 3. Paecilomyces farinosus J3 alleviates HUVEC tube formation on Matrigel. (A) HUVECs were plated at 2x104 cells/well in a Matrigel-coated 24-well plate, and then exposed to $0,0.1,0.3,1$ or $3 \mathrm{mg} / \mathrm{ml}$ of Paecilomyces farinosus $\mathrm{J} 3$ culture filtrate. After $24 \mathrm{~h}$, the culture medium was removed and the cells were fixed with $10 \%$ formalin. The cell morphology infiltrated into the Matrigel (A), and the relative tubular numbers (B) of the formed tubes were calculated. Bar, $10 \mu \mathrm{m}$. The results are shown as the average per field \pm SD of three independent experiments. CON, control. "Significant difference from the control (Paecilomyces farinosus $\mathrm{J} 3,0 \mathrm{mg} / \mathrm{ml}$ ), $\mathrm{P}<0.05$.

A

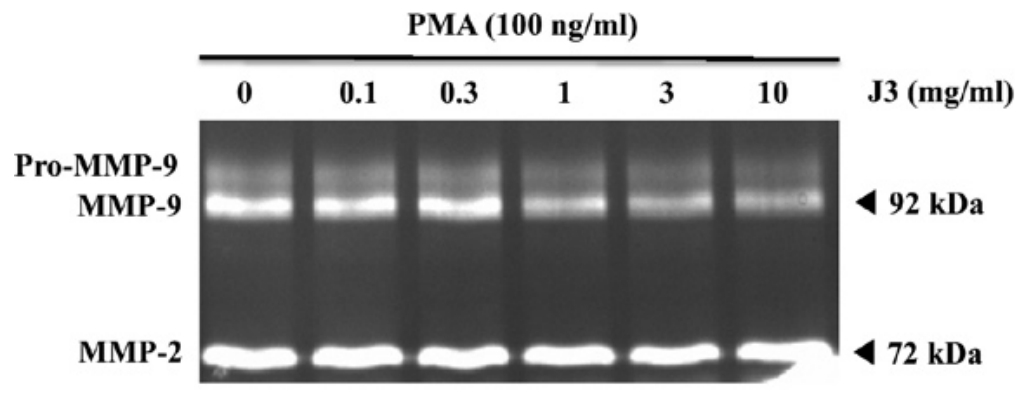

B

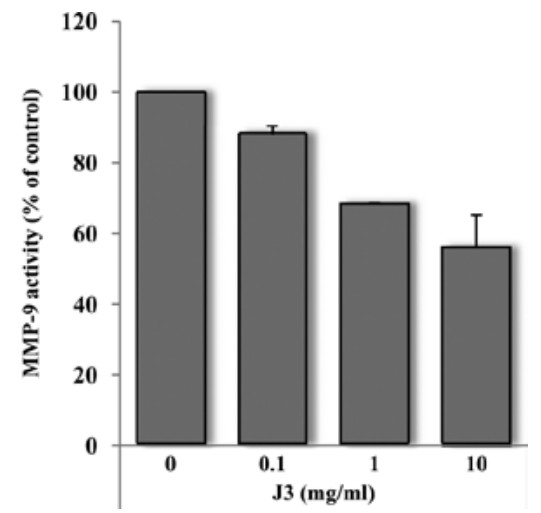

Figure 4. Paecilomyces farinosus J3 inhibits MMP-9 expression. (A) Proteins with gelatinolytic activity were identified by electrophoresis in the presence of SDS on $10 \%$ polyacrylamide gels containing $0.1 \%$ (w/v) gelatin. In brief, cell culture medium was obtained from cultured B16F1 cells in DMEM and PMA $(75 \mathrm{nM})$, with or without different concentrations of $\mathrm{J} 3$ for $24 \mathrm{~h}$ in 6-well culture dishes. The cultured medium was mixed with SDS-PAGE sample buffer in the absence of $\beta$-mercaptoethanol and DTT. Five microliters of sample were loaded onto a gel.

a level of $55 \%$ of the control at a concentration of $10 \mathrm{mg} / \mathrm{ml}$ (Fig. 4B). MMP-2 activity did not change by J3 treatment with or without PMA (Fig. 4B; data not shown). Additionally, the expression of other MMPs, as well as other tumor-related molecules (uPAR, Timp-1, Timp-2, Paxillin, Src and ARF-2), did not change after treatment with J3 (data not shown). However, the precise up- and down-stream signaling pathway involved needs to be investigated. 


\section{Discussion}

Traditional medicine utilizingplant and/or herbal extracts is believed to inhibit cancer cell growth and control the homeostasis of malignant cells in tissues or organs $(1,2)$. For many years, herbal extracts have been used as functional food materials in Oriental medicine, in order to maintain homeostasis in the body and to mitigate the symptoms of degenerative diseases $(18,19)$. Moreover, the tyrosinase-inhibitory activity of Cordyceps sp. extracts leads to the suppression of melanin production (20); these extracts therefore have a potential use in cosmetics. Additionally, the anti-depressant, anti-oxidative, anti-hepatitic, anti-diabetic and anti-aging activities of various extracts of Cordyceps sp. lead to a wide range of bioactivities in vitro, as well as in vivo (21-25). Paecilomyces sp. is also a type of entomogeneous fungus. The bioavailability and functionality of Paecilomyces sp. are more useful and potent than those of Cordyceps sp., in that the strain has beneficial effects on artificial cultivation and usefulness in host infections (26-29). This study was undertaken to investigate the anti-tumor effects of the culture filtrate of Paecilomyces farinosus $\mathrm{J} 3$. The results of a wound healing assay, invasion assay, HUVEC assay and gelatin zymography indicated that J3 inhibited B16 melanoma cell growth, thus demonstrating its anti-tumor potential. We therefore sought to examine the mechanisms involved in this cell growth inhibition by $\mathrm{J} 3$.

First, we examined the effect of the culture filtrate of J3 on cell migration using a wound healing assay in B16F10 melanoma cells. This cell line is a good model for the assessment of cell morphology, motility and proliferation (13-15). B16 cells migrated into the damaged wound, suggesting that migration is associated with various events in the cytoskeletal structure, such as actin polymerization and changes in the cell motility-related framework (30). J3 exerted a dose- and time-dependent inhibition of wound healing in B16 cells. This phenomenon strongly suggests that certain components in $\mathrm{J} 3$ are able to restrict cell motility, by means of cytoskeletal change and/or morphological features.

We investigated whether J3 can influence HUVEC differentiation into capillary-like tube formation. As metastatic potential is characterized by endothelial cell differentiation, in vitro angiogenic assays were performed to assess this potential with HUVECs by incubating the cells for $24 \mathrm{~h}$ with J3 on Matrigel. As capillary-like structures were observed in the HUVECs in the control, we attempted to confirm this by treatment with J3. As shown in Fig. 3A, in cell morphology the J3-treated HUVECs was markedly decreased in a dosedependent manner, suggesting that the tube formation was affected by $\mathrm{J} 3$ in a concentration- and time-dependent manner (Fig. 3B and data not shown).

Invasion assay are well-recognized in vitro angiogenic method for assessing invasion in B16F10 melanoma cells. Fig. 2 elucidates the $\mathrm{J} 3$ dose-dependent inhibition of cell invasion in B16F10 melanoma cells on Matrigel in a transwell assay. PMA-activated B16F10 cells underwent a 1.6-fold growth increase compared to the PMA non-treated control cells, whereas $\mathrm{J} 3$-treated cells $(10 \mathrm{mg} / \mathrm{ml})$ were inhibited via the process of the breakdown of the matrix at a level of $35 \%$ compared to the control, and a level of $21 \%$ compared to the
PMA-treated cells, although the activity was milder than that of $50 \mu \mathrm{M}$ dykellic acid (5,6; data not shown).

There are many types of matrix-degrading proteases in numerous types of cells (3). Of these, gelatinase is now well-known for its role in angiogenesis development, as the enzyme is activated during its passage through the blood vessels when tumor cells are under hypoxic conditions (4). We therefore investigated the effects of J3 on MMPs. RT-PCR analysis of MMP-1 to -28 revealed that only the expression of MMP-9 was reduced (data not shown). In Fig. 4A, by treatment with J3, the MMP-9 level (92 kDa) was decreased in a dosedependent manner, whereas the MMP-2 level was not. B16F10 melanoma cells did not secrete their pro-MMP-9 form into the medium, and this was not detected in the zymogram (Fig. 4A, above each $92 \mathrm{kDa}$ band). We previously showed that Oriental herbal medicines exhibit various anti-tumor activities. As chemicals from herbal extracts, such as dykellic acid $(5,6)$, methylselenol (31), gall extract of Wisteria floribunda (13), methylene chloride fraction of Geum japonicum Thunberg (14) and aqueous extract of Gastrodia elata Blume (15) are potentially toxic to tissues or organs, we sought to identify natural substances or food-borne biomaterial(s). Among the candidates is $\mathrm{J} 3$, since this fungus has no toxicity, as shown by animal experiments and single dose acute/chronic acute toxicity tests (data not shown).

In conclusion, we herein demonstrate that Paecilomyces farinosus $\mathrm{J} 3$ dose-dependently inhibits B16 cell migration and motility, and inhibits HUVEC tube formation in vitro, resulting in decreased levels of MMP-9. These findings, in combination with those of previous studies indicating that J3 inhibits a PMA-induced increase in MMP-9 expression, suggest that $\mathrm{J} 3$ may be a promising candidate for future development as an anti-tumor agent.

\section{Acknowledgements}

This study was supported by the BioGreen 21 (Agenda) Projects, RDA, Korea (2009101-060-005-001-02-00), and also in part by the Technology Development Program for Agriculture and Forestry, The Ministry of Food, Agriculture, Forestry, and Fisheries, Korea (on anti-asthmatic assay).

\section{References}

1. Khatami M: Yin and Yang in inflammation: duality in innate immune cell function and tumorigenesis. Expert Opin Biol Ther 8: 1461-1472, 2008.

2. Mahabeleshwar GH and Byzova TV: Angiogenesis in melanoma. Semin Oncol 34: 555-565, 2007.

3. Stamenkovic I: Extracellular matrix remodelling: the role of matrix metalloproteinases. J Pathol 200: 448-464, 2003.

4. Jakob C, Sterz J, Zavrski I, Heider U, Kleeberg L, Fleissner C, Kaiser $\mathrm{M}$ and Sezer O: Angiogenesis in multiple myeloma. Eur J Cancer 42: 1581-1590, 2006.

5. Woo JH, Park JW, Lee SH, Kim YH, Lee IK, Gabrielson E, Lee SH, Lee HJ, Kho YH and Kwon TK: Dykellic acid inhibits phorbol myristate acetate-induced matrix metalloproteinase-9 expression by inhibiting nuclear factor kappa B transcriptional activity. Cancer Res 63: 3430-3434, 2003.

6. Lee SH, Youk ES, Lee HJ, Kho YH, Kim HM and Kim SU: Dykellic acid inhibits drug-induced caspase-3-like protease activation. Biochem Biophys Res Commun 302: 539-544, 2003.

7. Coghlin $\mathrm{C}$ and Murray GI: Current and emerging concepts in tumour metastasis. J Pathol 222: 1-15, 2010 
8. Bourguignon LYW: Hyaluronan-mediated CD44 activation of RhoGTPase signaling and cytoskeleton function promotes tumor progression. Semin Cancer Biol 18: 251-259, 2008.

9. Rao YK, Fang SH and Tzeng YM: Evaluation of the antiinflammatory and anti-proliferation tumoral cells activities of Antrodia camphorate, Cordyceps sinensis, and Cinnamomum osmophloeum bark extracts. J Ethnopharmacol 114: 78-85, 2007.

10. Lee HM, Kim YJ, Kim HW, Lee DH, Sung MK and Park TS Induction of apoptosis by Cordyceps militaris through activation of caspase-3 in leukemia HL-60 cells. Biol Pharm Bull 29 670-674, 2006.

11. Alves SB, Rossi SR, Lopes RB, Tamai MA and Pereira RM: Beauveria bassiana yeast phase on agar medium and its pathogenicity against Diatraea saccharalis (Lepidoptera: Crambidae) and Tetranychus urticae (Acari: Tetranychidae). J Invertebr Pathol 81: 70-77, 2002.

12. Russell R and Paterson M: Cordyceps - a traditional Chinese medicine and another fungal therapeutic biofactory? Phytochemistry 69: 1469-1495, 2008.

13. Heo JC, Park JY, Lee JM, Kwon TK, Kim SU, Chung SK and Lee SH: Wisteria floribunda gall extract inhibits cell migration in mouse B16F1 melanoma cells by regulating CD44 expression and GTP-RhoA activity. J Ethnopharmacol 102: 10-14, 2005

14. Heo JC, Woo SW, Kweon MA, Son M, Yoon EK, Lee HK Choi WS, Cho KJ and Lee SH: A methylene chrolide fraction of Geum japonicum Thurnberg inhibits metastatic and angiogenic potential. Oncol Rep 19: 1399-1404, 2008.

15. Heo JC, Woo SU, Son M, Park JY, Choi WS, Chang KT, Kim SU, Yoon EK, Kim YH, Shin HM and Lee SH: Anti-tumor activity of Gastrodia elata Blume is closely associated with a GTP-Rasdependent pathway. Oncol Rep 18: 849-853, 2007.

16. Giannopoulou E, Dimitropoulos K, Argyriou AA, Koutras AK, Dimitrakopoulos F and Kalofonos HP: An in vitro study, evaluating the effect of sunitinib and/or lapatinib on two glioma cell lines. Invest New Drugs 28: 554-560, 2001.

17. Falkeholm L, Grant CA, Magnusson A and Moller E: Xylenefree method for istological preparation: a multicentre evaluation. Lab Invest 81: 1213-1221, 2001.

18. Halsted $\mathrm{CH}$ : Dietary supplements and functional foods: 2 sides of a coin? Am J Clin Nutr 77 (Suppl 4): 1001-1007, 2003

19. Ferrari CK: Functional foods, herbs and nutraceuticals: towards biochemical mechanisms of healthy aging. Biogerontology 5 : 275-289, 2004

20. Ji DB, Ye J, Li CL, Wang YH, Zhao J and Cai SQ: Anti-aging effect of Cordyceps sinensis extract. Phytother Res 23: 116-122, 2009 .
21. Hsu CH, Sun HL, Sheu JN, Ku MS, Hu CM, Chan Y and Lue KH: Effects of the immunomodulatory agent Cordyceps militaris on airway inflammation in a mouse asthma model. Pediatr Neonatol 49: 171-178, 2008.

22. Ohta Y, Lee JB, Hayashi K, Fujita A, Park DK and Hayashi T: In vivo anti-influenza virus activity of an immunomodulatory acidic polysaccharide isolated from Cordyceps militaris grown on germinated soybeans. J Agric Food Chem 55: 10194-10199, 2007.

23. Nishizawa K, Torii K, Kawasaki A, Katada M, Ito M, Terashita K, Aiso S and Matsuoka M: Antidepressant-like effect of Cordyceps sinensis in the mouse tail suspension test. Biol Pharm Bull 30: $1758-1762,2007$

24. Shi B, Wang Z, Jin H, Chen YW, Wang Q and Qian Y: Immunoregulatory Cordyceps sinensis increases regulatory $\mathrm{T}$ cells to Th17 cell ratio and delays diabetes in NOD mice. Int Immunopharmacol 9: 582-586, 2009.

25. Ko WS, Hsu SL, Chyau CC, Chen KC and Peng RY: Compound Cordyceps TCM-700C exhibits potent hepatoprotective capability in animal model. Fitoterapia 81: 1-7, 2010.

26. Zhang C, Zou X, Leluo G, Xu J and Xiang M: Prevention of type 1 diabetes by immature dendritic cells treated with an ethanol extract of Paecilomyces hepiali Chen mycelium. Methods Find Exp Clin Pharmacol 30: 421-429, 2008.

27. Lu HE, Jian CH, Chen SF, Chen TM, Lee ST, Chang CS and Weng CF: Hypoglycaemic effects of fermented mycelium of Paecilomyces farinosus (G30801) on high-fat fed rats with streptozotocin-induced diabetes. Indian J Med Res 131: 696-701, 2010.

28. Lang G, Blunt JW, Cummings NJ, Cole AL and Munro MH: Paecilosetin, a new bioactive fungal metabolite from a New Zealand isolate of Paecilomyces farinosus. J Nat Prod 68: 810-811, 2005.

29. Cheng Y, Schneider B, Riese U, Schubert B, Li Z and Hamburger M: Farinosones A-C, neurotrophic alkaloidal metabolites from the entomogenous deuteromycete Paecilomyces farinosus. J Nat Prod 67: 1854-1858, 2004.

30. Hata K, Hori K, Murata J and Takahashi S: Remodeling of actin cytoskeleton in lupeol-induced B16 2F2 cell differentiation. J Biochem 138: 467-472, 2005.

31. Kim A, Jung JY, Son M, Lee SH, Lim JS and Chung AS: Long exposure of non-cytotoxic concentrations of methylselenol suppresses the invasive potential of B16F10 melanoma. Onco Rep 20: 557-565, 2008. 